inoculation treated mice contained an average of $0.7 \mathrm{ml}$. ascites $(0.1-2.9 \mathrm{ml}$.) whereas control mice had $3.8(\mathbf{1} \cdot 6-5 \cdot 8) \mathrm{ml}$. In each case hæmatocrit determinations showed an average packed white cell content of 2.5 per cent approximately.

No significant growth restraint was produced in a transplanted $C 3 H$ mammary cancer in mice treated parenterally with $60 \mathrm{mgm} . / \mathrm{kgm}$. polyporic acid for periods of 14 days.

Cancer Research Laboratory,

$$
\text { J. F. BURTON }
$$$$
\text { B. F. CAIN }
$$

Auckland Division,

British Empire Cancer Campaign Society (Ine.), Cornwall Geriatric Hospital, Greenlane, S.E.4,

Auckland, New Zealand.

\section{Sporidesmium Bakeri Recorded from Victoria, Australia}

STRong evidence was produced ${ }^{1,2}$ in 1958 that facial eczema of sheep in New Zealand is caused by ingestion of spores of a fungus identified as Sporidesmium bakeri. Lately I carried out experimental work in New Zealand during January-March, 1959, which involved inter alia the isolation of Sporidesmium spores from pasture. On return to Australia a search made of pastures in southern Victoria disclosed the presence of a fungus which appeared superficially identical to the New Zealand Sporidesmium. A culture was forwarded to the Commonwealth Myco. logical Institute, who report that it is indeed Sporidesmium bakeri.

Some three years ago a minor outbreak of a disease similar to New Zealand facial eczema was reported from certain areas in south-eastern Victoria. Within the past few months a much more serious outbreak of what definitely appears to be facial eczema has been reported from a number of properties in this area. This outbreak appears to have followed an unusually dry summer followed by a rainy period, conditions similar to those which lead to facial eczema outbreaks in New Zealand. The finding that the same fungus exists in Victoria supports the possibility that the two diseases are identical, and the isolate is being administered to sheep as a preliminary check.

\section{B. S. JANES}

Merrindale Biological Research Station,

Imperial Chemical Industries of Australia and New Zealand Ltd.,

Croydon, Victoria. July 28.

1 Percival, J. C., and Thornton, R. H., Nature, 182, 1095 (1958). 1
2 Anon., $N . \dot{Z} . J$. Agric., 97 (4), 328 (1958)

\section{Sporidesmium bakeri and Facial Eczema of Sheep in the Field}

THIs communication records a relationship between the occurrence of Sporidesmium bakeri and facial eczema disease of sheep in the field. It has already been demonstrated that experimental animals fed cultures of this fungus developed characteristic lesions of the disease ${ }^{1,2}$.

At the Manutuke Research Station, Gisborne, a facial eczema research farm of the New Zealand Department of Agriculture, two, 1-acre fields (No. 20 and No. 31), of perennial rye grass, white clover have been closely mown at 7-14 day intervals, with motor lawn-mowers since the spring flush of pasture growth in October, 1958. In field No. 20, the mower clippings were returned to the pasture by the expedient of leaving the catcher off the mower, while in No. 31 the catcher was attached and the clippings were removed. Neither field was grazed from October, 1958, to January, 1959, and under this mowing treatment both fields had a high proportion of white clover in the sward.

In field No. 20 there was an accumulation of litter resulting from the return of clippings and in early January, 1959, S. bakeri was observed to be growing and sporing profusely on litter and dead grass and clover leaves. Spores were found to blow in the wind, particularly when the surface of the ground was disturbed, and microscopical examination revealed spores adhering to the leaves of living grass and clover leaves. Thus spores on both dead and live plant material would be ingested by stock. In field No. 31 little was sparse and spores were present in lower numbers.

Field No. 10 was employed as a control and was a typical, grazed summer pasture, 4-6 in. long and containing a high proportion of old dead ryegrass stalk and leaf, in which spores were scarce and difficult to detect.

Spore counts were made on pasture samples cut with hand shears $\frac{1}{2}$ in. above the ground. Fresh pasture (25 gm.) was shaken for $1 \mathrm{~min}$. in tap water ( $250 \mathrm{ml}$. plus one drop 'Teepol'), and filtered through a 2 -mm. sieve. Spores in the filtrate were counted with a Neubauer blood cell counting chamber. 10 samples of grass were collected in each field, 5 equally spaced along each of two diagonals across the field. Spores in five $1 \mathrm{sq}$. mm. squares (centre and four corners) were counted in each of two counting chambers prepared for each sample, and counts expressed as mean values. Statistically the accuracy and reproducibility of this method was good. The results recorded in Table 1 do not necessarily indicate the total spore contents of the pastures as the percentage recovery of spores by this technique is not known.

Table 1. CoznTS OF SPORES OF S. bakeri per 1 sQ. MM. COUNTINa CHAMBER

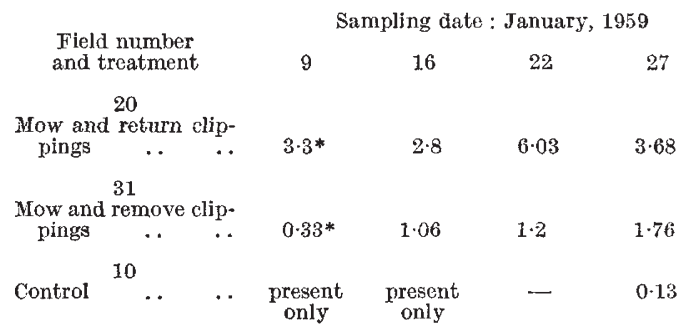

Spores per gm. fresh-weight pasture are obtained by multiplying these

* Results from bulk samples.

The increase in spore count in field No. 20 on January 22 was due to the colonization by $S$. bakeri of fresh clippings added to the pasture when the field was mown on January 16.

On January 9, five shorn Romney wether lambs were placed in each of fields Nos. 20 and 31 on a basis of paired live-weights, and 10 lambs were put in field No. 10. These lambs were judged to be free of facial eczema at the time because twelve lambs from the same flock, killed a day earlier showed no evidence of liver damage. The lambs in field No. 20 showed early symptoms of photosensitivity on January 16, and by January 26 three had developed facial lesions. In field No. 31 one lamb developed facial lesions on January 27, and on this date all five lambs appeared to be suffering 